\title{
Minimising unsustainable yield: Ten failing European fisheries
}

\begin{abstract}
Ten European fish stocks recognised by the European Union as "outside safe biological limits" are considered in light of widespread reforms to fisheries legislation in 2013, particularly the legal responsibility to exploit these resources sustainably. Given that some of these stocks are - as of $2013-$ fished at over $150 \%$ the recommended intensity and many have been outside of these limits for the entirety of their assessment history, the utilisation of traditional fisheries management measures of sustainability are questioned and tougher approaches such as "zero-catch" and long-term, expansive spatial closure scenarios are considered. Finally, the pervasive issue of datadeficiency (the status of $54 \%$ of European stocks) is briefly considered, with specific reference to the understudied West of Scotland and North Sea stock of European seabass (Dicentrarchus labrax).
\end{abstract}

\section{Keywords}

Common Fisheries Policy (CFP) reform; Maximum sustainable yield (MSY); Unsustainable fishing; North Sea cod; Data-deficient stocks; Marine protected areas (MPAs)

\section{1.}

\section{Introduction}

The legal response to nations fishing beyond maximum sustainable yield (MSY) is enshrined in international law and the illegality of unsustainable fishing activity has been established in principle [1]. Recent changes in court access and the reforms to the European Union's (EU) Common Fisheries Policy (CFP) mean that for the first time MSY obligations may be enforceable through the courts. Sufficient legal instruments exist at national and supranational levels to force sustainable practice on EU fishing operations [2]. However, the interpretation (and, therefore, implementation) of these legal instruments is complicated by among other things the variety of conflicting and contradictory definitions of MSY in use [3] and the large proportion of EU stocks described as "data-deficient" (106 out of 198, or 54\%, as of 2013 [4]).

A clear legal interpretation of MSY can be drawn from the US case State of Maine v Krepps 563 F. 2nd 1043, 1046 [1]:

The term 'maximum sustainable yield' [...] refers to a scientific appraisal of the safe upper limits of harvest which can be taken consistently year after year without diminishing the stock [...] so that the stock is truly inexhaustible and perpetually renewable [5]

This establishes a legal precedent for the term but uncertainty still exists in the interpretation of which form of "scientific appraisal" is used: fisheries science, conservation biology, ecosystem services, economics or social science (all disciplines with different working definitions of a sustainable fishery). The implementation and delivery of CFP reform will see complex 
academic interaction while these differing approaches triangulate to comply with the law. A tandem approach to the issue is presented:

- First: the development of a robust, scientific and cross-disciplinary approach capable of demonstrating sustainability to the satisfaction of the numerous academic constituencies,

- Second: the identification of fishing operations requiring immediate intervention because it is clear that their operations are not sustainable on any common sense measure [1].

This study adopts the second approach by investigating ten European fisheries that the EU have themselves "red-listed" as outside safe biological limits [4] and explain why these are not sustainable. In some cases legal measures have already been put in place to restore these failing stocks and these cases are therefore used to demonstrate the sorts of actions that the law now requires.

\section{1}

Complexities of sustainable EU fisheries

From both a biological and administrative perspective, the management of the fishing activities of $28 \mathrm{EU}$ nations is a necessarily complex task. Target species may breed in the territorial waters of one nation but spend other life history stages in the jurisdiction of another [6], entire stocks can shift their historical range due to climatic shifts [7], and overexploitation in one zone can go unnoticed until depletion is observed elsewhere [8]. The latter phenomenon has been observed in the EU's shared North Sea Atlantic cod (Gadus morhua) fishery, in which Danish vessels not fishing for cod may inadvertently remove juveniles and the prey on which the species depends, leading to observed cod catch rate reduction among UK cod vessels [8]. In this case, overexploitation clearly cannot be avoided without managing the interdependencies of both fisheries [8].

The CFP provides a political mechanism through which nations that compete for access to fish stocks can address the biological issues described above (as well as offering fair access for all nations to the shared Exclusive Economic Zone of the entire Union) [9]. However, this politicisation of fisheries management - particularly the application of Total Allowable Catches (TACs) for fish stocks and their subsequent division into national quotas - has led to ongoing criticism that the policy promotes national interests above genuine attempts to ensure sustainable resource management [10]. This is especially evident in the consistent setting of TAC designations above scientifically recommended limits by the European Commission (EC), the EU's executive body [11]. In addition to biological uncertainties and political interference, realising sustainable fishery practice is further hampered by the need to foster agreements with non-EU nations - such as Iceland and Norway - whose fleets exert fishing pressure within EU waters. The unilateral Atlantic mackerel (Scomber scombrus) quota increase in 2009 by (non-EU) Iceland and the Faroe Islands exposed the instability of these agreements and emphasised the dangers of short-sighted catch maximisation [12]. 


\section{2}

Progress towards sustainability

In spite of the considerable difficulties involved, recent progress in CFP implementation has been made: particularly when the improvement of certain key stocks is considered [13]. For example, according to the EU's own indices of biological robustness, of 41 stocks evaluated between 2001 and 2010, 44\% (18 stocks) were exploited at a sustainable level of fishing mortality in 2010, compared to $12 \%$ (five stocks) in 2001 [13]. The present study will focus on those stocks that the EU itself has "red-listed" and examine how they have reached a benchmark of overexploitation and what restorative measures have been and are being applied. Additionally, "data-deficient" stocks are briefly considered. Table 1 summarises the 2013 status of red-listed and datadeficient stocks across the 12 broad EU fisheries administration zones and highlights the overexploited species in each of these zones.

\section{Table 1 here}

Table 2 shows the definitions of the various biological measures of stock performance (measures widely referred to in this study) as outlined by the EU's fishery science advisory body, the International Council for the Explorations of the Seas (ICES).

\section{Table 2 here}

\section{2.}

\section{Case studies}

The following ten case studies are a selection of the 23 fisheries the EU regarded in 2013 as "outside safe biological limits" [4]. Of those 23, the following 11 stocks were excluded, as they currently have zero-catch or "N/A" TACs: EU-wide for porbeagle (Lamna nasus), three stocks of cod (G. morhua) and spiny dogfish (Squalus acanthias), Black Sea turbot (Psetta maxima), Baltic Sea (not including the Gulf of Riga) herring (Clupea harengus) and Barent Sea and Norwegian sea redfish (Sebastes spp.). The Irish Sea whiting (Merlagius merlangus) is also excluded as ICES considers that no targeted fishery remains for this species and monitors it only as by-catch [15]. The two red-listed horse mackerel (Trachurus trachurus) fisheries are described in one section (2.6) as both fisheries target the wide-ranging "Western stock" of this species.

Fig. 1 shows that nine of the remaining "red-listed" stocks (those considered by our study) are currently well outside the sustainable limit of one or both of the two clearest indicators of stock health: fishing mortality rate (F) and spawning stock biomass (SSB). Each of the nine stocks has spent a significant proportion of the period in which it has been assessed outside of these limits, in some cases the entirety of that study period (Fig. 2). The final stock considered in the study - Celtic Sea Nephrops - does not have estimates for these measures and so is not included in Figs 1 or 2 (but is discussed in section 2.7). 
Figure 1 here

Figure 2 here

\section{1}

North Sea cod (Gadus morhua)

Atlantic cod (Gadus morhua) has been commercially exploited within the North Sea eco-region since the early Middle Ages [16], with the nations of Belgium, Denmark, France, Germany, the Netherlands, Norway, Poland, Sweden and the United Kingdom (UK) exerting the most significant fishing pressure. ICES has collected fishing mortality and stock biomass data on this population since 1963 and considers one distinct stock to occupy three management zones: Sub-Area IV (North Sea) and Divisions VIId (Eastern Channel) and IIla (Skagerrak) [17].

Changing historical patterns of effort have applied to the fisheries targeting the North Sea cod stock [18]. Variable (but consistently high) proportions of cod removal have been instigated by the technological development of vessels capable of longer journeys, displaced effort as a result of disputed territorial grounds and administrative changes in quota distribution [18]. Retrospective analysis of fishing mortality rates revealed that between 19792003 stocks were subjected to nearly four times the exploitation level required to generate maximum sustainable yield $\left(F_{m s y}\right)$ and that in 1998 the spawning stock biomass (SSB) of the population fell below the lowest threshold needed to maintain reproductive capacity ( $B_{\text {lim; }}$ set for this population at $70,000 t$ ) [19]. In 2012, SSB was adjudged to have neared $B_{\text {lim, but still remains well below }}$ even the precautionary level required to produce MSY $\left(\mathrm{Bpa}_{\mathrm{p}}\right)$ [19].

Since the early $21^{\text {st }}$ century, various management intervention schemes have been instituted for these stocks by the two administrative blocks responsible for fisheries activity in the North Sea: the EU and Norway [19]. These have entailed drastic reductions in the total allowable catch (TAC), variable reductions in days at sea (according to vessels' gear type and mesh size) and the adoption of more extensive monitoring and surveillance regulations [19]. Although subject to a great deal of revision of management measures, the requirements of the EU-Norway agreement (particularly since its December 2008 update) have succeeded in reducing fishing mortality to below the level required to theoretically prevent collapse $\left(F_{p a}\right)$ for the first time since the late 1960s [17].

In spite of these reported successes, various studies have suggested that the reduction in fishing mortality has come too late to prevent irrevocable, longterm genetic and population disturbance. One comparison between individual size/age datasets from the early $20^{\text {th }}$ and $21^{\text {st }}$ centuries showed that the Skagerrak juvenile population displays reduced variability in body size, suggesting that it may have genetically stabilised against small, slow-growing and large, fast-growing individuals (that is, the population has become less genetically diverse) [20]. The absence of consistent datasets of age and size 
means that this response cannot be conclusively linked to harvest selection (i.e. fishing pressure) in this stock, though correlation between these variables has been known to occur in Atlantic cod [21]. It has also been suggested that warmer spring water temperatures - induced by climate change - may hamper juvenile recruitment [22]. Perhaps the most extreme suggestion is that the North Sea sub-population has already suffered functional extinction and that, consequently, the opportunity to effectively rebuild the stock through a complete closure of the fishery may have passed [23].

The North Sea cod stock has experienced a long history of temporary and real-time spatial closures; the most prominent being the 1987 cod box (designed to protected the large 1985 year class) and the $2001 \mathrm{cod}$ closed area (designed to protect an area where $80 \%$ of cod was caught the previous year and to help implement a significant TAC decrease). Neither measure delivered its intended impact, the former having been applied too late to prevent high fishing mortality in the juvenile year-class and the latter being too temporally and spatially restricted to have the desired effect [24]. The application of large closed areas (or marine protected areas [MPAs]) to reinvigorate cod stocks has been demonstrated in the George's Bank closure where the resident cod biomass increased by 50\% [25]). Despite this impressive figure, the UK government refuses to concede that MPAs could succeed in reinvigorating North Sea cod biomass unless combined with significant further effort reduction [26].

\section{2}

Irish Sea cod (Gadus morhua)

The Atlantic cod stock of ICES sub-area VIla, (namely the Irish Sea) is considered distinct from that of the North Sea as it occupies a separate broad eco-region: the Celtic and West of Scotland [27]. The range of this stock is limited and occupies a management zone $7 \%$ the size of the North Sea population $\left(50,111 \mathrm{~km}^{2}\right.$ compared to $\left.701,870 \mathrm{~km}^{2}\right)$. The UK, Ireland and Belgium are the principal nations with historical fishing interests and are, therefore, allocated the largest share of the fishery's TAC $(56.8 \%, 34.9 \%$ and $7.4 \%$ in 2011, respectively). Excessive fishing mortality occurred later in the Irish than North Sea. Flim was passed in 1987 and the consequent SSB decline to below $B_{\lim }(6,000 t)$ was observed in 1993. The stock remains outside of these critical limits in 2013 [27].

European Commission responses to SSB decline were initially focussed on a patchwork of spatial closures, in what was thought to be the location of spawning grounds [28]. However, these measures were criticised by both scientists and fishers for their inclusion of "derogations" within the closed area, allowing for the continuation of certain non-cod fisheries but excluding other non-cod fisheries [29]. This contentious measure was followed by statutory restrictions on the size and construction of the "cod-ends" of trawl nets and slashing of the stock's TAC. Overall, the suite of management measures adopted for this fishery have been criticised for a lack of focus to reduce exploitation. Given this, together with the stock's small size, range and 
high level of fishing mortality, it is little surprise that it remains outside biological safe limits [29].

Broader scale stressors such as climate change could compound attempts to recover the Irish Sea cod stock, particularly as its latitudinal position represents the second most southerly point of the species' range, (i.e. behind the Eastern Channel) [30]. Theoretical modelling of the stock's response to predicted sea surface temperature (SST) rises has shown that only with an

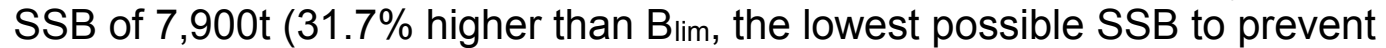
collapse) can Irish Sea cod be guaranteed to withstand the predicted effects of climatic variability [31]. In response to these wider concerns and the continued languishing of SSB below $B_{\text {lim, ICES currently advises that no }}$ directed cod fisheries take place in the Irish Sea [25].

\section{3}

Faroe Plateau haddock (Melanogrammus aegelfinus)

The waters around the island nation of the Faroe Islands have supported fisheries since at least 1872, when the use of British-bought wooden vessels for sea fishing was first recorded [32]. Topography and a strong tidal regime means that the $200 \mathrm{~m}$-depth plateau around the Islands experiences high levels of year-round primary productivity, supporting stocks of multiple whitefish species such as cod, haddock and saithe [33]. The ICES Faroe Grounds statistical Division also includes the Faroe Bank; an offshore bank with a depth profile and species assemblage closely related to those of the plateau [33].

Haddock in the Atlantic exhibits significantly higher recruitment variability than G. morhua [34] and has, therefore, experienced a changeable exploitation history. The distinct stock of the Faroe Grounds (ICES Division Vb; including sub-divisions Vb1 [Faroe Plateau] and Vb2 [Faroe Bank]) is fished primarily by the Faroe Islands itself, with small catches from the UK, France, Norway and Iceland having largely dissipated in recent years [35]. The stock was fished at a level capable of producing MSY intermittently from 1974 to 1995, but mortality rose above precautionary levels in 1998-99 and 2003-4. SSB is now at its lowest observed level and has remained between 16 and 39\% below the minimum level needed to preserve reproductive capacity since 2010 [35].

As it is not a member of the European Union, the Faroese government has fostered its own innovations in addressing the sustainability of stocks within its EEZ. The most notable of these was the 1996 introduction of an ambitious plan of effort-based management in the form of total allowable effort (TAE) restrictions as opposed to catch-based management, via TACs [35]. This is an example of input - as opposed to output - control; whereby the variable which an authority can manipulate (the amount of allocated fishing in days) is restricted, as opposed to one that is subject to a great deal of stochastic variability (the amount of fish caught). However, whilst providing a useful case study of alternative management strategies, the Faroese "fishing days" scheme has not averted stock decline and cannot be shown to offer more long-term stability than a TAC system [36]. The apparent non-consideration of 
technological creep may explain the failure of the scheme to successfully reduce catches in the primarily long-lining Faroese fleet. Several changes during the period of the TAE scheme - including small incremental increases in the number of daily hooks set and the introduction of swivel lines and skewed hooks - meant that "effort days" was shown to be a poor indicator of fishing intensity [37].

$M$. aegelfinus stocks elsewhere in EU waters have demonstrated the smaller mean body size and reduced fecundity of an overexploited resource [38], and although this has not been investigated in the Faroese population, the species is being harvested unsustainably and ICES has advised that no fishery activity be exerted on the stock [35]. The only form of spatial protection currently employed in Faroese waters is a ban on trawling gear below 200m [35] and temporary closures of fishing zones if bycatch or juvenile catch reaches certain levels. The contraction of this fishery has led to calls from nongovernmental organisations (NGOs) for greater protection, particularly for the Faroe Bank [39].

\section{4}

Rockall haddock (Melanogrammus aegelfinus)

The remote plateau and banks surrounding the Rockall islet in the North Atlantic has supported a productive but variable fishery for over 200 years, with the first known vessels arriving there to fish from Shetland in 1805 [40]. This area has less diverse fish assemblages than in the adjacent west coast of Scotland shelf [41]. Haddock was not historically considered the dominant target species in the area, with Atlantic cod and common ling (Molva molva) supporting the largest share of early $20^{\text {th }}$ century catches [40].

Given this low historical effort, ICES has only monitored haddock fishing mortality and biomass indices in Rockall (designated as division VIb) since 1991 [42]. Over that relatively brief period of study, SSB has declined by $79 \%$ from a 1995 high of 29,501t to the 2013 low of 6,224t, though fishing mortality has stabilised to a level below $F_{\text {msy }}$ [42]. Modern haddock catches in the area have been split between the UK, Norway and the Faroe Islands, though - as with many EU fisheries zones - Rockall contains a non-EU (international) Regulatory Area administered by the North East Atlantic Fisheries Commission (NEAFC), which is also fished by Russian Federation vessels [42].

As previously stated, North Atlantic haddock populations display significantly larger recruitment variability than those of cod and this is exacerbated by the lower growth rates exhibited in Rockall haddock [43] and a local decline in the zooplankton Calanus finmarchicus, a prey species for the stock [42]. Both of these factors are accounted for in the low TAC $(1,620 \mathrm{t})$ proposed for 2014 , which reflects ongoing uncertainty around the strength of the 2012 year-class.

Spatial protection is in place in the area in the form of demersal and static gear restrictions in four zones known to host deep-water corals (Lophelia spp.); North West Rockall, Logachev Mounds, West Rockall Mounds and Empress of British Banks [44]. Additionally, spatial closure has been utilised 
specifically for fisheries management with the designation of a "Haddock Box" in the ICES statistical rectangle 42D5 in 2001, which prevents the use of all fishing gear except long-lines [45]. In spite of over a decade of protection, the box has not succeeded in altering fishery selection patterns in adjacent fishing zones. ICES attributes this failure to poor coverage, stating that the box does not include all zones where juvenile haddock are known to occur and advises that the EU discards ban may have a more dramatic effect on juvenile preservation by dis-incentivising the capture of small individuals [46].

\section{5}

\section{Gulf of Riga herring (Clupea harengus membras)}

The semi-enclosed brackish water of the Gulf of Riga, within the Baltic Sea, supports an almost self-contained herring stock, providing a homogenous but abundant supply of zooplanktonic prey and a low-salinity refuge from predators such as $G$. morhua $[47,48]$. Tax records obtained from the Riga Treasury College indicate that the area has maintained herring fishing (as well as flounder [Platichthys flesus] and eelpout [Zoarces viviparus]) since at least 1685 , and that historical climatic conditions influenced the yield of this stock [49].

Climatic variability has continued to strongly influence the success of the modern fishery, which takes place in the subdivision 28.1 (the small zones of the Baltic Sea are demarcated numerically, the system of numerals and letters having been deprecated in this Sub-Area) and is exclusively exploited by Estonia and Latvia [47]. Water temperature in subdivision 28.1 is known to strongly influence zooplankton abundance and hence herring recruitment, such that severe winters can negatively impact year-class strength [50]. Various studies have shown that the stock-related variables that are traditionally thought to drive recruitment (density dependence, individual fecundity etc.) are complicated by this particular stock's close relationship with climatic patterns $[48,49,50]$. SSB and mortality projections must therefore account for the uncertainty in recruitment, though it must be considered a success that SSB has not been below a putative $B_{\text {msy }}$ since 1987 [47]. However, fishing mortality has lingered above the level needed to maintain MSY every year since 1995 and was above precautionary limits in the period 1996-2007 (in one year by 50\%) and again in 2009 [47]. A negative trend in mean weight and condition at age (i.e. the biomass of an individual when it reaches spawning age) was observed in the late 1990s, with values far below those recorded in the 1980s [47]. It is clear that though long-term physical decline in herring individuals is not currently restricting this fishery, this degradation could leave the stock more susceptible to any increase in the variability of the climatic conditions on which its recruitment depends [51].

Given the relative - if precarious - stability of this stock, fisheries management measures have not been imposed on the trawler and trapnet fleets of Estonia and Latvia, though ICES observes that vessel performance has been growing as older vessels are decommissioned and replaced [47]. There are seven statutory MPAs in the Gulf of Riga, with five managed by the Latvian Nature Conservation Agency and two by the Estonian Environmental Board. However, six of these are focussed on adhering to the EU's non- 
marine Habitats Directive and Birds Directive and thus still allow sustainable resource extraction [52]. With this initial network in place, ICES is in the process of providing advice to HELCOM (the governing body which implements the Convention on the Protection of the Marine Environment of the Baltic Sea Area) on how to utilise this network to support its fisheries, including the still-threatened Gulf of Riga herring [53].

\section{6}

Migratory horse mackerel (Trachurus trachurus)

Migratory species that enter EU waters are co-managed with the regional fishery management (RFMO) body that manages the adjacent international waters in which that species also resides. Three migratory horse mackerel stocks are entirely managed by the EU, but management strategies for these are distinctly different from those for less mobile fish species given that horse mackerel occur across a far broader range, thereby encompassing several ICES sub-areas. The stock that ranges across subdivisions Ila, IVa, Vb, Vla, VIla-c, e-k and sub-area VIII is referred to as the "Western stock" and this is fished by up to 14 nations in the North Sea (IVa) [54].

ICES has only been monitoring horse mackerel since 1982, however the UK's Centre for Fisheries and Aquaculture Science (CEFAS) collected catch data for it across the continental shelf in 1975 which revealed a relatively modest total catch for that year of just below $60,000 t$ [55]. This increased by close to an order of magnitude by the 1990s, reaching nearly 550,000t in 1995 and consequently inflated the 1997 fishing mortality index of the stock to nearly $115 \%$ over the intensity required to produce MSY [54]. Though fishing mortality then stabilised below $F_{m s y}$, it has now risen again to $48 \%$ above this limit [54].

ICES do not consider the methodology for assessing SSB in this stock to be robust enough to generate a $B_{\text {msy }}$ level [56]. The triennial egg production survey used to generate an SSB proxy assumes that all eggs counted will be spawned: ICES considers that this compromise causes unacceptable bias in the survey's data. The current index - though it must be treated with caution - has shown an SSB decline of 80\% between 1988 and 2013 [54]. The decline can be explained by the sporadic recruitment patterns of $T$. trachurus; the 1988 peak in SSB being the maturation of an outstanding year-class in 1982 that has not since been repeated and has been rapidly fished down [57].

Whilst it is clear from ICES assessments that fishing intensity remains above recommended limits, the difficulty in refining a suitable measure of projected SSB currently limits the successful application of any management measures to this widely dispersed stock. Any measure proposed must balance effectiveness with feasibility, but problematically, $T$. trachurus has been shown to exhibit indeterminate annual fecundity, meaning that a single annual measure will not be sufficiently accurate and that multiple surveys per annum must be completed [58]. Given that the effectiveness of MPAs in protecting migratory scombrid or carangid species is currently poorly understood and largely untested [59], spatial protection represents less of a priority for this stock than the evolution of appropriate SSB measurement devices. 


\section{7}

Celtic and Irish Sea Norway lobster (Nephrops norvegicus)

Nephrops trawl fisheries encircle Ireland, extending across the Celtic and Irish Seas, up the west coast and further offshore across Porcupine Bank [60]. The earliest recorded catches of this widespread crustacean species in Europe are from 1950, when 9,300t were landed. Since then this figure has increased by over 8 times to a high of 75,999t in 2007 [61]. The Republic of Ireland and the United Kingdom exert the highest fishing pressure in the Irish and Celtic Sea and Nephrops trawling is their first and second most valuable fishery, respectively $[62,63]$.

$N$. norvegicus is an infaunal species, that lives in burrows in sandy or muddy sediment and can aggregate in high densities over a limited area.

management of its stocks therefore requires the use of considerably smaller spatial units than that offered by the setting of TACs at ICES Sub-Area or even Division level [60]. Accordingly, stocks are managed according to functional units (FU), each encompassing several scattered statistical rectangles within Sub-Area VII. There are seven FUs, covering the same number of distinct stocks [60]. Landings data at FU level has only been collected since 2009 and whilst localised fluctuations have taken place, the red-listing of this fishery is attributed to the excessive level of bycatch (particularly of cod, haddock, whiting, hake, monkfish, and megrim) recorded due to the widespread use of small $(\leq 80 \mathrm{~mm})$ mesh sizes [60]. In the Firth of Clyde FU - a stock not managed in this zone - a ratio of $9 \mathrm{~kg}$ of discards to $1 \mathrm{~kg}$ of Nephrops has been recorded [64].

Whilst Nephrops stocks are not known to exhibit the negative responses to exploitation shown by demersal whitefish species, climatic factors have been shown to affect the stability of catch rates within established FUs. Catch rates of the remotest stock in the zone - that in FU 16, the raised seabed area of Porcupine Bank - display a negative relationship in response to intensity of the North Atlantic Oscillation [NAO]. The latter is a spatially-defined fluctuation of atmospheric sea level pressure which, in a positive phase, produces stormy, wet and windy conditions across the entirety of Sub-Area VII. The cause of Nephrop's response to the oscillation is poorly understood, though it is thought that the environmental conditions of a positive NAO could hamper the species' planktonic prey abundance and the success of its larval settlement [65]. Because of the excessive bycatch associated with the fishery for Nephrops as a whole, together with the climatic uncertainties involved for the species, a greater level of management restriction is needed either in the form of an agreed TAC or broader-scale protection. Given the known effects of bottom-trawling on benthic biodiversity in muddy sediments [66] and the limited mobility of the target species, the use of a patchwork of spatial protection measures - such as those utilised in the Isle of Man scallop fisheries [67] are one appropriate measure that should be introduced.

\section{8}

Western English Channel plaice (Pleuronectes platessa) 
The English Channel is thought to accommodate up to $80 \%$ of all spawning and recruitment activity for $P$. platessa in the British Isles and therefore it supports a large proportion of national fishery activity for the species [68]. Internationally, the UK is the principal fishing nation for $P$. platessa in the English Channel, though stocks are also harvested by French and Belgian vessels. In 2011 , the UK claimed $70 \%$ of all plaice landings in the Channel [69].

Two stocks of the species occupy the English Channel, one in the Eastern portion of the Channel (Division VIId) and the other in the Western (VIIe). The former stock is considered data-deficient, but - perversely - both stocks are managed by a single TAC [69]. The Western Channel stock has remained above the fishing mortality rate needed to produce MSY for the entirety of its ICES monitoring period since 1980, and in 2007 was 3 times the recommended level; though efforts have since been made to reduce exploitation [69]. SSB remains well above $B_{m s y}$, largely due to an exceptional year-class in 2010.

In addition to fishing mortality concerns, the Western English Channel plaice fishery has also been scrutinised because of the destructive nature of its principal gear type: beam trawling with chain-mat. In addition to reducing benthic biodiversity [70], the disturbance caused by this method can negatively impact the success of the fishery itself, according to the dominant sediment type. In the Celtic Sea, mean size at age of $P$. platessa was tested against increased trawling intensity and was observed to decline on gravel habitats and increase on sandy habitats. Fish were smaller on more intensely trawled gravel habitats due to reduced availability of fragile, epibenthic prey and larger on trawled sandy habitats due to increased availability of infaunal benthic prey [71]. Finally, a minor concern for this fishery surrounds discarding over-quota plaice catch. Though this is thought be less than in other UK $P$. platessa fisheries [69], concern is justified given that between 20.4-62.7\% of discarded plaice have been observed to die in this fishery. Levels depend on the month of capture, with higher death rates observed when individuals were caught in peak spawning season and were therefore in poorer physical condition [72].

A broad range of fisheries management measures have been applied to the mixed-gear fleet targeting the Western English Channel plaice stock; including a $12 \mathrm{~nm}$ from shore ban on all beam trawlers with $>221 \mathrm{~kW}$ main engine output, a minimum mesh size for all gear types, a minimum landing size (MLS) of $>27 \mathrm{~cm}$ and effort restrictions in terms of kiloWatt days fishing per year [72]. Whilst these are considered effectively implemented measures, they have consistently failed to reduce fishing mortality hence a more dramatic scheme of decommissioning beam-trawling vessels is currently underway [69]. Spatial protection measures exist in the form of an inshore trawling ban [72] but these are not specifically targeted at preserving juvenile habitats. Their omission is key, given the known co-location of juvenile habitats and Channel fishing grounds [68]. 
Irish Sea sole (Solea solea)

S. solea in the Irish Sea (division VIla) is primarily targeted by a chain-mat gear beam trawl fleet, though landings have never been high in this fishery and it is shared between only four nations [73]. Belgium exerts the highest fishing pressure, and took $76 \%$ of the catch in 2012, with the remainder allocated to the UK and Ireland [73]. The first European target fishery for $S$. solea began in the 1960s in the North Sea with the addition of beam trawler chains used to encourage demersal flatfish up from the substrate.

Monitored by ICES since 1970, this stock's spawning biomass has experienced a sevenfold decline since 1986 and is currently at its lowest recorded level: $56 \%$ below the lowest observed annual SSB estimate followed by an increase the following year [73]. Fishing mortality has since declined, but remains at its precautionary limit and is still nearly double theoretical $F_{m s y}$. Though the amount of beam trawling in the fishery reduced by $76 \%$ between 2003 and 2012, it is clear that other gear types still exert a significant pressure on this stock and that its collapse may still be imminent [74].

Whilst the stock is being harvested at unsustainable levels, the population does not appear to exhibit the symptoms of fisheries induced evolution. In fact, environmental gradients may have a greater effect on recruitment success than fishing pressure amongst EU sole stocks [75]. Spatial restrictions have not been utilised in the management of this stock, though an overlapping closure for cod spawning has been in place in the Irish Sea since 2000 [73].

\subsection{0}

West of Scotland whiting (Merlangius merlangus)

M. merlangus in the West of Scotland (Division Vla) is a stock whose biological robustness has been impacted through both a mismanaged targeted fishery and the subsequent expansion of Nephrops fisheries in the same area [76]. The levels of fishing mortality and SSB required to realise MSY have not been identified for $M$. merlangus, but instead, a precautionary approach aimed at preventing complete collapse (i.e. SSB falling to below $B_{\text {lim) }}$ has been identified. However, in reality, SSB passed below Blim in 2000 and has remained below this threshold since then.

Delayed management action came in the form of massive effort reduction from 2002 onwards, which succeeded in bringing fishing mortality well below $F_{\text {lim. }}$ However, whilst effort has been significantly reduced in the larger-mesh trawl (TR1) sector, the same is not true of the smaller-mesh trawl (TR2) sector. The TR2 fleet is dominated by vessels targeting Nephrops and is estimated to be responsible for up to $80 \%$ of under-size $M$. merlangus discards [76]. Discard rates of under-sized $M$. merlangus have been observed to be significantly higher in the TR2 Nephrops fleet of Division Vla than the mixed demersal fleet and to be higher than under-size G. morhua discards in either fleet [77]. The specific combination of this gear type and species is therefore more economically damaging than other comparable fishery activities in the same zone. 
As stated in section 1.3, the stagnation of the West of Scotland whiting stock can be attributed to ineffective cross-stock management and the inflexibility of TAC (or output-based) approaches [36]. Though collateral improvement is expected to occur for this stock through the Cod Recovery Zone in the West of Scotland, it is clear that spatial or effort restrictions will only be effective when legislation exists to manage both fisheries concurrently, taking into account all interactions between the two stocks.

\section{3.}

\section{Data deficient stocks}

Over half of EU fish stocks are unassessed and considered "data-deficient" by the European Commission [4]. Of the 12 broad EU fishing zones, six contain more assessed than unassessed stocks (Table 1). Data deficient stocks dominate the Mediterranean, the Black Sea and the north-western and southwestern waters of the continental shelf [78]. The EU itself acknowledges that cost-effectiveness and lack of existing management in these fisheries are two broad causes of data-deficiency. In the absence of the full complement of recruitment, mortality and biomass data, alternative methods can be used to generate stock assessment, utilising proxies and modelled estimates. Additionally, in 2013, ICES developed and implemented a Data-Limited Stocks (DLS) approach, which aims to provide precautionary quantitative advice on data-deficient stocks [78].

The risks of sustained data-deficiency are well illustrated by the case of exploited seabass (Dicentrarchus labrax) populations across EU waters. A key challenge for fisheries managers and policy-makers is ensuring the sustainability of an extracted resource when relatively little is known about the species' biology and this difficulty is exemplified by the current status of $D$. labrax.

\section{1}

West of Scotland and North Sea European sea bass (Dicentrarchus labrax) Phylogeographic methodologies (principally genetic and microsatellite markers) have been used to attempt to establish which European seabass communities are demographically distinct: arguably the first step in evolving management plans for an exploited fish stock [79, 80]. Whilst Mediterranean populations have been identified as genetically distinct, genomic structures have not been defined across the North Atlantic stock [79], which is considered by ICES to occupy eight statistical divisions, with a total area of $608,980 \mathrm{~km}^{2}$ [81]. In addition to uncertainty around the extent of this population and whether it can be treated homogenously, spawning, mortality and recruitment data are not available for a long enough time-series to produce conclusive trends, a fact also compounded by the unquantified - but identifiably significant - pressure exerted by recreational fisheries [80]. Those data that do exist begin in 1985; where only estimates of fishing mortality and SSB relative to mean values within that time-series are available. These limited data show a $42 \%$ relative decline in SSB over eight years (2005-12) and a $187 \%$ increase in fishing mortality over 11 years (2002-12); both clear signs of rapid overexploitation [81]. Between 1985 and 2009, landings 
increased over four times (with a slight reduction in 2010-12). The fishery also became exploited by a growing number of nations, with France and Belgium reporting significant $D$. labrax catches in 2012 (where each nation registered zero commercial catches prior to 1996 and 2003, respectively).

ICES provide rough annual estimates of the recreational catch of $D$. labrax recorded in France and the Netherlands and even these raw figures show catch levels comparable to these nations' commercial fleets. In 2010, French recreational catch that was retained (i.e. not released) was $940 t$, representing a further $28 \%$ of catch in addition to French commercial catch of the species $(3,400 t)$. From a socio-cultural perspective, D. labrax is an important species, having been rated the most prized fish by recreational sea anglers in a survey by the UK's National Federation of Sea Anglers [82].

Despite EU-level data gaps (which mean the stock has no designated TAC), this fishery has been subject to localised (i.e. national) management measures. The UK evolved a series of measures - such as mesh regulations, an MLS of $36 \mathrm{~cm}$ and the seasonal closure of 34 nursery areas - that have been applauded as effective on a local scale [83]. However, the effectiveness of these measures is complicated by the complexity of this fishery's user groups, which comprise inshore and recreational fishers targeting small $D$. labrax individuals and offshore fishers targeting larger individuals [84]. This difficulty is further compounded by competing national interests, which are not governed by shared legislation. For example, a widely used method of targeting $D$. labrax is pair-trawling where two vessels are used to tow a single trawl net. Due to high levels of marine mammal bycatch, this practice was banned up to $12 \mathrm{~nm}$ from UK shores in 2005 [84]. However, because this legislation only applies to vessels in the UK, the practice still continues among French and Belgian vessels, although the number of these is low. Given that pair-trawling is also extremely effective in boosting catch rate [85], the significance of this method in the excessive harvesting of $D$. labrax must be assessed and managed through a united, cross-national legislative approach.

\section{3.}

\section{Discussion}

The case studies presented clearly show that the requirement to fish sustainably is not being fulfilled in the fisheries considered. As a result, legal proceedings could conceivably be brought to bear on them, particularly given the extent (Fig. 1) and duration (Fig. 2) of unsustainable exploitation in most stocks examined. However, whilst the enshrinement in EU law of the imperative to attain MSY is undoubtedly welcome, the use of a traditional fisheries management paradigm of sustainability has been shown to be ineffective in these fisheries. Reasons for this include political intrusion [11, $29,36]$, delayed management response [17, 23, 56], non-consideration of climatic and prey species variation in stock estimates [31, 42, 47, 50, 71, 75], systemic incentivisation of discarding $[59,68,75]$ and unforeseen interactions between exploited stocks $[8,76,77]$. 
Given the proportional growth in sustainably exploited, non-data-deficient EUmonitored stocks (i.e. those not considered by this study) [13], the observed state of these ten fisheries must be considered evidence of a declining trend in stock mismanagement. It is therefore vital to identify similarities among these so-called "problem" stocks, particularly in terms of ineffective management responses and suggested improvements. Of the 2014 EU TACs for the ten stocks, five were above ICES recommended limits, three were equal to or below those limits and two require further agreement before establishment (Table 3). It is noteworthy that of the five TACs set above recommended limits, four were those stocks where a "zero-catch" or "no directed fishery" response was advised. Three of these zero-catchrecommended stocks (west Scotland whiting, Irish Sea sole and cod) were accorded relatively low TACs $(<300 t)$, which can be considered partially a reflection of their limited ranges (i.e. within small, enclosed coastal seas) and estimated optimum biomass. However, the fact that previous years' Irish sole and cod TACs have not even been met (i.e. what little quota was afforded was not used), suggests these reduced TACs are an admission of a contracting fishery resource and that, even when drastic action is required, the wholesale closure of a fishery - even in a geographically limited, coastal fishery - is a management response that will be avoided at all costs [27, 73].

\section{$\underline{\text { Table } 3 \text { here }}$}

In the cases of Irish Sea sole, cod and west Scotland whiting, clearly catch reduction has been too piecemeal and the continuing mismatch between scientific recommendation and management action may have consigned these fisheries to inexorable decline (or monitoring only as a bycatch species, as in the case of Irish Sea whiting [151). For other "problem" stocks, limited understanding of exploited species' ecology and the difficulty of applying scientific concerns to well-established fishery activity compound the political controversy of catch control. The Celtic and Irish Sea Nephrops fishery, for example, represents a species requiring adaptation of traditional methods of TAC designation. With the relatively recent discovery that the best index of abundance for this species is the abundance of its burrows, management recognised in the mid 1980s that exploited stocks exist (and therefore require monitoring) at a far finer scale than those of finfish; this recognition coming only once the fishery was already reporting landings comparable to those reported in 2013 [60]. At the opposite end of the scale, the range of the Western Horse mackerel stock is so large that traditional methods of biomass estimation (i.e. population size) are simply not possible, yet a well-established history of exploiting this species already exists across several nations (having the largest quota of the ten studied stocks reflects the extent of this multinational commercial activity) [54]. Finally, stocks that display large and poorly understood variability (such as the Gulf of Riga herring stock) emphasise the need to incorporate broader environmental variables into traditional catch control estimates.

In contrast to the rapidly declining coastal, non-migratory, demersal problem stocks, the emergent and less well understood Horse mackerel, herring and Nephrops fisheries are benefiting from science-led management approaches; 
the relative contemporaneity of, for example, the Nephrops fishery has fostered innovation in vessels' gear design and interest in networks of spatial closures [86]. However, each of these fisheries has been monitored and managed for a considerable period of time (Fig. 2) and, in many cases, many of the same management measures that have succeeded in restoring sustainable biomass in other stocks - catch reduction, effort reduction, gear innovation, spatial closures - have not been successful. The continuing inability to promote long-term commercial viability in the North Sea cod stock, for example, demonstrates that, even in spite of the investment of significant finance and expertise, there is inherent difficultly in managing a single stock in isolation (particularly one that has been subject intense historical exploitation) [87].

Achieving sustainability in these stocks may mean considering less traditional and potentially more severe measures, such as the implementation of closed fisheries (i.e. zero catch) [27], long-term spatial closures [28, 29] or the application of the ecosystem approach [88]. The use of MPAs as a potential tool for fishery management has also gained momentum [26, 39, 53], and though concerns remain about the displacement of effort to other fishing grounds [89], that cannot be seen as an acceptable reason to ignore the potential for MPAs to benefit fisheries. It is clear that habitat protection, particularly for species that have a benthic stage in their life cycle, is a key measure in the implementation of MSY $[66,68]$.

The FAO-advocated ecosystem approach to fisheries management (EAFM) requires that all exploitation activity be incorporated into an overarching strategy which considers all known dynamic ecosystem processes - including environmental fluctuation and trophic interaction - in deciding appropriate measures for stock control [88]. The need for such an approach in Europe is emphasised by the capture of non-target, and/or over-quota species (i.e. bycatch), an issue only resolved through the ecologically and commercially wasteful practice of discarding (to be prohibited in the reformed CFP) or financially undesirable gear improvements. European fishing activity is predisposed towards landing a mixture of species and, as such, is already impacting multiple facets of these exploited species' ecosystems and therefore requires the broader scale thinking and ambition inherent in the EAFM [90].

On a practical level, the implementation of EAFM in the EU requires the synthesis of ICES' long-published single stock assessments into an overarching strategic assessment in which the contribution of fishing activity on each stock is measured in relation to the sum of all activity [90]. Such an approach was begun theoretically in 2013 for North Sea stocks and involves positing a variety of scenarios in which TACs are altered and then attempting to model-predicted outcomes modelled, leading to the eventual selection of the most desirable [91]. Given the complexities of the different nations, vessel sizes and gear types utilised in the exploitation of European marine ecosystems, the evaluation of fleet dynamics within EU fisheries is a vital component in EAFM implementation, though the associated challenge of gathering sufficient reliable fleet data is significant [92]. 
Finally, alternative approaches to fisheries management can only be

successfully implemented if sufficient levels of exploited species data are collected; the issue of data-deficiency can only be resolved through adaptive, quantitative management of under-surveyed stocks and such management is clearly in its nascent form in Europe [78]. The slow contraction of the wideranging seabass stock of the North Sea and the West of Scotland demonstrates how traditional sustainability measures (i.e. the attaining of MSY) can fail when a fishery is not formally recognised and understood i.e. accorded its own TAC [79, 81]. This is problematic where several nations already exploit a stock and are free to base unilateral quota decisions solely on national interests [84]. With the increase of legal drivers for sustainability [1], a better-informed public, and because it is the right thing to do, it is clear that past poor performance cannot continue. This leaves fisheries managers, scientists, politicians and fishers themselves with the task of repairing stocks. This study shows that the first tentative steps are being made in that direction, but there is a long way to go.

\section{Acknowledgments}

Research in this report was funded by the Blue Marine Foundation. The authors would like to thank Dr. Callum Roberts for his support and advice.

\section{References}

[1] Appleby, T., Everard, M., Palmer, R. \& Simpson, S. (2013). Plenty more fish in the sea? A working paper on the legal issues related to fishing beyond maximum sustainable yield: A UK case study. Working paper. University of the West of England. Downloaded from http://eprints.uwe.ac.uk/22111/1/pmf_final2\%20(3).pdf on $19^{\text {th }}$ December 2013.

[2] Proelss, A., \& Houghton, K. (2012). The EU Common Fisheries Policy in light of the precautionary principle. Ocean \& Coastal Management, 70, 22-30.

[3] Hilborn, R., \& Stokes, K. (2010). Defining overfished stocks: have we lost the plot?. Fisheries, 35(3), 113-120.

[4] European Commission (2013). Fishing TACs and quotas 2013. Downloaded from http://ec.europa.eu/fisheries/documentation/publications/poster_tac201 3_en.pdf on 8th November 2013.

[5] Cited in Curcio, P. L. (1997) Fishermen's Dock Coop., Inc. v. Brown: Judicial Review of Optimum Yield. Determinations. Ocean and Coastal Law Journal 3 259-274.

[6] Mikalsen, K. H., \& Jentoft, S. (2008). Participatory practices in fisheries across Europe: Making stakeholders more responsible. Marine Policy, 32(2), 169-177. 
[7] Walther, G. R., Post, E., Convey, P., Menzel, A., Parmesan, C., Beebee, T. J., ... \& Bairlein, F. (2002). Ecological responses to recent climate change. Nature, 416(6879), 389-395.

[8] Daw, T., \& Gray, T. (2005). Fisheries science and sustainability in international policy: a study of failure in the European Union's Common Fisheries Policy. Marine Policy, 29(3), 189-197.

[9] EU (2013). The common fisheries policy: Management of fisheries in the EU. Downloaded from http://ec.europa.eu/fisheries/cfp/ on 12 November 2013.

[10] Khalilian, S., Froese, R., Proelss, A., \& Requate, T. (2010). Designed for failure: A critique of the Common Fisheries Policy of the European Union. Marine Policy, 34(6), 1178-1182.

[11] Salomon, M., \& Holm - Müller, K. (2012). Towards a sustainable fisheries policy in Europe. Fish and Fisheries, 14(4), 625-638. DOI: 10.1111/faf.12009

[12] Hannesson, R. (2013). Sharing the Northeast Atlantic mackerel. ICES Journal of Marine Science: Journal du Conseil, 70(2), 259-269.

[13] Cardinale, M., Doerner, H., Abella, A., Andersen, J. L., Casey, J., Döring, R., ... \& Stransky, C. (2013). Rebuilding EU fish stocks and fisheries, a process under way?. Marine Policy, 39, 43-52.

[14] ICES (2012a). Acronyms and terminology used in ICES advice. ICES Advice 2012, Book 1. Downloaded from http://www.ices.dk/community/Documents/Advice/Acronyms_and_termi nology.pdf on 12 March 2014.

[15] ICES (2012b). Whiting in Division VIla (Irish Sea). ICES Advice June 2012, Book 5. Downloaded from http://www.ices.dk/sites/pub/Publication\%20Reports/Advice/2012/2012/ whg-iris.pdf on 31st October 2013.

[16] Roberts, C. (2007). The unnatural history of the sea. Island Press.

[17] ICES (2013a). Cod in Subarea IV (North Sea) and Divisions VIId (Eastern Channel) and Illa West (Skagerrak). ICES Advice June 2013, Book 5. Downloaded from http://www.ices.dk/sites/pub/Publication\%20Reports/Advice/2013/2013/ cod-347.pdf on 30th October 2013.

[18] Thurstan, R. H., Brockington, S., \& Roberts, C. M. (2010). The effects of 118 years of industrial fishing on UK bottom trawl fisheries. Nature Communications, $1,15$. 
[19] OECD (2012). Rebuilding Fisheries: The Way Forward. OECD Publishing. http://dx.doi.org/10.1787/97892641-en

[20] Olsen, E. M., Carlson, S. M., Gjøsæter, J., \& Stenseth, N. C. (2009). Nine decades of decreasing phenotypic variability in Atlantic cod. Ecology letters, 12(7), 622-631.

[21] Olsen, E. M., \& Moland, E. (2011). Fitness landscape of Atlantic cod shaped by harvest selection and natural selection. Evolutionary Ecology, 25(3), 695-710.

[22] Rogers, L. A., Stige, L. C., Olsen, E. M., Knutsen, H., Chan, K. S., \& Stenseth, N. C. (2011). Climate and population density drive changes in cod body size throughout a century on the Norwegian coast.

Proceedings of the National Academy of Sciences, 108(5), 1961-1966.

[23] Froese, R., \& Quaas, M. (2012). Mismanagement of the North Sea cod by the European Council. Ocean \& Coastal Management, 70, 54-58.

[24] Darby, C., Hutton, T., Andrews, J., Gurney, W. S. C., Beveridge, D., and Hiddinck, J. G. 2006. Investigations into closed area management of the North Sea cod. Cefas Contract report, C2465. 110 pp.

Downloaded from http://www.defra.gov.uk/fish/science/pdf/mpareportcod.pdf on 8th November 2013.

[25] Fogarty, M. J., \& Murawski, S. A. (2005). Do marine protected areas really work?. Oceanus, Woods.

[26] Department for Environment, Food and Rural Affairs [DEFRA], (2005). The potential role of Marine Protected Areas (MPAs) for fisheries management purposes: Fisheries Directorate's summary of the main conclusions emerging from three desk studies. Fisheries Directorate. Downloaded from http://archive.defra.gov.uk/environment/marine/documents/science/mp areport-defrasummary.pdf on 8th November 2013.

[27] ICES (2012c). Cod in Division VIla (Irish Sea). ICES Advice June 2012, Book 6. Downloaded from http://www.ices.dk/sites/pub/Publication\%20Reports/Advice/2012/2012/ cod-iris.pdf on 31st October 2013.

[28] ICES (2003). Working Group on the Assessment of Northern Shelf Demersal Stocks (WGNSDS). ICES Document CM 2003/ ACFM: 01. $558 \mathrm{pp}$.

[29] Kelly, C. J., Codling, E. A., \& Rogan, E. (2006). The Irish Sea cod recovery plan: some lessons learned. ICES Journal of Marine Science: Journal du Conseil, 63(4), 600-610. 
[30] Drinkwater, K. F. (2005). The response of Atlantic cod (Gadus morhua) to future climate change. ICES Journal of Marine Science: Journal du Conseil, 62(7), 1327-1337.

[31] Beggs, S. E., Cardinale, M., Gowen, R. J., \& Bartolino, V. (2013). Linking cod (Gadus morhua) and climate: investigating variability in Irish Sea cod recruitment. Fisheries Oceanography. DOI: 10.1111/fog. 12043

[32] Ministry of Fisheries and Natural Resources (2013). Fishing History. Fishin.Fo Living off the sea in the Faroe Islands. Downloaded from http://www.fishin.fo/Default.aspx?ID=8661 on 4th November 2013.

[33] Pedersen, S.A., Madsen, J. and M. Dyhr-Nielsen (2004). Global International Waters Assessment Faroe Plateau, GIWA Regional assessment 13. University of Kalmar on behalf of United Nations Environment Programme. 64pp.

[34] Fogarty, M. J., Myers, R. A., \& Bowen, K. G. (2001). Recruitment of cod and haddock in the North Atlantic: a comparative analysis. ICES Journal of Marine Science: Journal du Conseil, 58(5), 952-961.

[35] ICES (2013b). Haddock in Division Vb. ICES Advice 2013, Book 4. Downloaded from http://www.ices.dk/sites/pub/Publication\%20Reports/Advice/2013/2013/ had-faro.pdf on 4th November 2013.

[36] Baudron, A., Ulrich, C., Nielsen, J. R., \& Boje, J. (2010). Comparative evaluation of a mixed-fisheries effort-management system based on the Faroe Islands example. ICES Journal of Marine Science: Journal du Conseil, 67(5), 1036-1050.

[37] Eigaard, O. R., Thomsen, B., Hovgaard, H., Nielsen, A., \& Rijnsdorp, A. D. (2011). Fishing power increases from technological development in the Faroe Islands longline fishery. Canadian Journal of Fisheries and Aquatic Sciences, 68(11), 1970-1982.

[38] Wright, P. J., Gibb, F. M., Gibb, I. M., \& Millar, C. P. (2011). Reproductive investment in the North Sea haddock: temporal and spatial variation. Marine Ecology Progress Series, 432, 149-160.

[39] Schmidt, S. F., O. S. Tendal, and E. Magnussen. (2003). The Faroe Bank - A Potential MPA. WWF's Showcase Examples for the OSPAR System of Marine Protected Areas (MPAs). Downloaded from http://www.ngo.grida.no/wwfneap/Publication/briefings/FaroeBank.pdf on 5th November 2013.

[40] Blacker, R. W. (1982). Rockall and its fishery. Ministry of Agriculture, Fisheries and Food, Directorate of Fisheries Research. Downloaded from 
http://www.cefas.defra.gov.uk/publications/lableaflets/lableaflet55.pdf on 4th November 2013.

[41] Neat, F., \& Campbell, N. (2011). Demersal fish diversity of the isolated Rockall plateau compared with the adjacent west coast shelf of

Scotland. Biological Journal of the Linnean Society, 104(1), 138-147.

[42] ICES (2013c). Haddock in Division VIb (Rockall). ICES Advice 2013, Book 5. Downloaded from http://www.ices.dk/sites/pub/Publication\%20Reports/Advice/2013/2013/ had-rock.pdf on 4th November 2013.

[43] Finina, E. A., Khlivnoy, V. N., \& Vinnichenko, V. I. (2009). The Reproductive Biology of Haddock (Mellanogrammus aeglefinus) at the Rockall Bank. Journal of Northwest Atlantic Fishery Science, 40, 59-73.

[44] Hall-Spencer, J. M., Tasker, M., Soffker, M., Christiansen, S., Rogers, S. I., Campbell, M., \& Hoydal, K. (2009). Design of Marine Protected Areas on high seas and territorial waters of Rockall Bank. Marine Ecology Progress Series, 379.

[45] North East Atlantic Fisheries Committee (2013). Closures on the Hatton and Rockall Banks and Haddock Box 2013. Downloaded from http://www.neafc.org/closures/hatton-rockall on 4th November 2013.

[46] ICES (2013d). ICES Request from NEAFC on the closure area and additional measures for the protection of juvenile haddock on Rockall Bank. ICES Advice 2013, Book 5. Downloaded from http://www.ices.dk/sites/pub/Publication\%20Reports/Advice/2013/Speci al\%20requests/NEAFC_protection_of_juveniles_of_Rockall_haddock.p df on 4th November 2013.

[47] ICES (2013e). Herring in Subdivision 28.1 (Gulf of Riga). Downloaded from http://www.ices.dk/sites/pub/Publication\%20Reports/Advice/2013/2013/ her-riga_201304142205.pdf on 5th November 2013.

[48] Kotta, J., Kotta, I., Simm, M., \& Põllupüü, M. (2009). Separate and interactive effects of eutrophication and climate variables on the ecosystem elements of the Gulf of Riga. Estuarine, Coastal and Shelf Science, 84(4), 509-518.

[49] Gaumiga, R., Karlsons, G., Uzars, D., \& Ojaveer, H. (2007). Gulf of Riga (Baltic Sea) fisheries in the late 17th century. Fisheries Research, 87(2), 120-125.

[50] Ojaveer, E., Arula, T., Lankov, A., \& Shpilev, H. (2011). Impact of environmental deviations on the larval and year-class abundances in the spring spawning herring (Clupea harengus membras L.) of the Gulf 
of Riga (Baltic Sea) in 1947-2004. Fisheries Research, 107(1), 159168.

[51] Raid, T., Kornilovs, G., Lankov, A., Nisumaa, A. M., Shpilev, H., \& Järvik, A. (2010). Recruitment dynamics of the Gulf of Riga herring stock: density-dependent and environmental effects. ICES Journal of Marine Science: Journal du Conseil, 67(9), 1914-1920.

[52] Helsinki Commission (2013). Baltic Sea Protected Areas Database. Downloaded from http://bspa.helcom.fi/ on 5th November 2013.

[53] ICES (2013f) Managing fisheries in Baltic Marine Protected Areas (BALTFIMPA). Downloaded from http://www.ices.dk/news-andevents/news-archive/news/Pages/Managing-Fisheries-in-Baltic-MarineProtected-Areas-(BALTFIMPA).aspx on 5th November 2013.

[54] ICES (2013g). Horse mackerel (Trachurus trachurus) in Divisions Ila, IVa, Vb, Vla, VIla-c, e-k, and Subarea VIII (Western stock). ICES Advice 2013, Book 9. Downloaded from http://www.ices.dk/sites/pub/Publication\%20Reports/Advice/2013/2013/ hom-west.pdf on 5th November 2013.

[55] Lockwood, S. J., \& Johnson, P. O. (1977). Horse mackerel. Directorate of Fisheries Research.

[56] De Oliveira, J. A., Darby, C. D., \& Roel, B. A. (2010). A linked separable-ADAPT VPA assessment model for western horse mackerel (Trachurus trachurus), accounting for realized fecundity as a function of fish weight. ICES Journal of Marine Science: Journal du Conseil, 67(5), 916-930.

[57] Roel, B. A., \& De Oliveira, J. A. (2007). Harvest control rules for the Western horse mackerel (Trachurus trachurus) stock given paucity of fishery-independent data. ICES Journal of Marine Science: Journal du Conseil, 64(4), 661-670.

[58] Armstrong, M. J., \& Witthames, P. R. (2012). Developments in understanding of fecundity of fish stocks in relation to egg production methods for estimating spawning stock biomass. Fisheries Research, $117,35-47$.

[59] Dueri, S., \& Maury, O. (2013). Modelling the effect of marine protected areas on the population of skipjack tuna in the Indian Ocean. Aquatic Living Resources.

[60] ICES (2013h). Nephrops in Subarea VII. ICES Advice 2013, Book 5. Downloaded from http://www.ices.dk/sites/pub/Publication\%20Reports/Advice/2013/2013/ Nep-VII-Intro.pdf on 5th November 2013. 
[61] Food and Agriculture Organization of the United Nations (2011). FishStat Global Capture Production 1950-2011. Downloaded from http://www.fao.org/fishery/topic/16140/en on 6th November 2013.

[62] Sea Fisheries Protection Authority (2013). 2012 Landings. Downloaded from http://sfpa.oghamtech.ie/Sea-

FisheriesConservation/FisheriesQuotas/FishLandings/FishLandings20 12.aspx on 6th November 2013.

[63] Marine Management Organisation (2012). UK Sea Fisheries Statistics 2011. Downloaded from from

http://www.marinemanagement.org.uk/fisheries/statistics/documents/uk seafish/2011/final.pdf on 6th November 2013.

[64] Bergmann, M., Wieczorek, S. K., Moore, P. G., \& Atkinson, R. J. A. (2002). Discard composition of the Nephrops fishery in the Clyde Sea area, Scotland. Fisheries Research, 57(2), 169-183.

[65] Herraiz, I. G., Torres, M. A., Fariña, A. C., Freire, J., \& Cancelo, J. R. (2009). The NAO index and the long-term variability of Nephrops norvegicus population and fishery off West of Ireland. Fisheries Research, 98(1-3).

[66] Queirós, A. M., Hiddink, J. G., Kaiser, M. J., \& Hinz, H. (2006). Effects of chronic bottom trawling disturbance on benthic biomass, production and size spectra in different habitats. Journal of Experimental Marine Biology and Ecology, 335(1), 91-103.

[67] Beukers-Stewart, B. D., Vause, B. J., Mosley, M. W., Rossetti, H. L., \& Brand, A. R. (2005). Benefits of closed area protection for a population of scallops. Marine Ecology Progress Series, 298, 189-204.

[68] Lauria, V., Vaz, S., Martin, C.S., Mackinson, S and Carpentier, A (2011). What influences European plaice (Pleuronectes platessa) distribution in the eastern English Channel? Using habitat modelling and GIS to predict habitat utilisation. ICES Journal of Marine Science, 68(7), 1500-1510. doi:10.1093/icesjms/fsr081

[69] ICES (2013i). Plaice in Division VIle (Western Channel). ICES Advice 2013, Book 5. Downloaded from http://www.ices.dk/sites/pub/Publication\%20Reports/Advice/2013/2013/ ple-echw.pdf on 5th November 2013.

[70] Jennings, S., Dinmore, T. A., Duplisea, D. E., Warr, K. J., \& Lancaster, J. E. (2001). Trawling disturbance can modify benthic production processes. Journal of Animal Ecology, 70(3), 459-475.

[71] Shephard, S., Brophy, D., \& Reid, D. G. (2010). Can bottom trawling indirectly diminish carrying capacity in a marine ecosystem?. Marine biology, 157(11), 2375-2381. 
[72] Revilla, A.S., Broadhurst, M.K., Millarc, R.B (2013). Mortality of adult plaice, Pleuronectes platessa and sole, Solea solea discarded from English Channel beam trawlers. Fisheries Research, 147, 320-326.

[73] ICES (2013j). Sole in Division VIlla (Irish Sea). ICES Advice 2013, Book 5. Downloaded from http://www.ices.dk/sites/pub/Publication\%20Reports/Advice/2013/2013/ sol-iris.pdf on 5th November 2013.

[74] Vanhaecke, H (2013). The Irish Sea Sole-stock: A "sole" Belgian problem?. Institute for Agricultural and Fisheries Research, North Western Waters Regional Advisory Council, Dublin. Downloaded from http://nwwrac.org/admin/publication/upload/ILVO_Action_Plan_Irish_S ea_NWWRAC_HV.pdf on 7th November 2013.

[75] Mollet, F., Engelhard, G. H., Vainikka, A., Laugen, A. T., Rijnsdorp, A. D., \& Ernande, B. (In press). Spatial variation in growth, maturation schedules and reproductive investment of female sole Solea solea in the Northeast Atlantic. Journal of Sea Research.

[76] ICES (2013k). Whiting in Division Vla (West of Scotland). ICES Advice 2013, Book 5. Downloaded from http://www.ices.dk/sites/pub/Publication\%20Reports/Advice/2013/2013/ whg-scow.pdf on 13 November 2013.

[77] Fernandes, P. G., Coull, K., Davis, C., Clark, P., Catarino, R., Bailey, N., ... \& Pout, A. (2011). Observations of discards in the Scottish mixed demersal trawl fishery. ICES Journal of Marine Science: Journal du Conseil, 68(8), 1734-1742.

[78] O'Brien, C. \& Le Quesne, W. (2013). Data Deficient Fisheries in EU waters. Report for the European Parliament's Directorate-General for Internal Policies. Downloaded from http://www.europarl.europa.eu/document/activities/cont/201306/201306 19ATT68058/20130619ATT68058EN.pdf on 13 November 2013

[79] Coscia, I., \& Mariani, S. (2011). Phylogeography and population structure of European sea bass in the north - east Atlantic. Biological Journal of the Linnean Society, 104(2), 364-377.

[80] Chistiakov, D. A., Hellemans, B., Haley, C. S., Law, A. S., Tsigenopoulos, C. S., Kotoulas, G., ... \& Volckaert, F. A. (2005). A microsatellite linkage map of the European sea bass Dicentrarchus labrax L. Genetics, 170(4), 1821-1826.

[81] ICES (2013I). European sea bass in Divisions IVbc, VIla, and VIId-h (Irish Sea, Celtic Sea, English Channel, and southern North Sea). ICES Advice 2013, Book 5. Downloaded from 
http://www.ices.dk/sites/pub/Publication\%20Reports/Advice/2013/2013/ bss-47.pdf on 5th November 2013.

[82] Angling Trust (2013). Sea Angling. Downloaded from http://www.anglingtrust.net/page.asp?section $=40$ on 8 th November 2013.

[83] Pawson, M. G., Pickett, G. D., \& Smith, M. T. (2005). The role of technical measures in the recovery of the UK sea bass (Dicentrarchus labrax) fishery 1980-2002. Fisheries research, 76(1), 91-105.

[84] Pawson, M. (2009). The contribution of science to management of the North Sea cod (Gadus morhua) and UK sea bass (Dicentrarchus labrax) fisheries: can we do better?. Advances in Fisheries Science: 50 Years on From Beverton and Holt, 155.

[85] Sainsbury, J.C. (1996). Commercial Fishing Methods (3rd edition). Fishing News Books, Oxford, UK.

[86] Johnson, M. L., \& Johnson, M. (2013). The ecology and biology of Nephrops norvegicus (Vol. 64). Academic Press.

[87] Ulrich, C., Reeves, S. A., Vermard, Y., Holmes, S. J., \& Vanhee, W. (2011). Reconciling single-species TACs in the North Sea demersal fisheries using the Fcube mixed-fisheries advice framework. ICES Journal of Marine Science: Journal du Conseil, 68(7), 1535-1547.

[88] Plagányi, É. E. (2007). Models for an ecosystem approach to fisheries (No. 477). Food \& Agriculture Organization of the United Nations.

[89] Jennings, S. (2009). The role of marine protected areas in environmental management. ICES Journal of Marine Science: Journal du Conseil, 66(1), 16-21.

[90] Wilson, D. C. K. (2012). European mixed fisheries as a complex commons. Natures Sciences Sociétés, 20(1), 66-74.

[91] ICES (2013m). Multispecies considerations for the North Sea stocks. ICES Advice 2013, Book 6. Downloaded from http://www.ices.dk/sites/pub/Publication\%20Reports/Advice/2013/2013/ mult-NS.pdf on 17 March 2014.

[92] Gascuel, D., Merino, G., Döring, R., Druon, J. N., Goti, L., Guenette, S. \& Mackinson, S. (2012). Towards the implementation of an integrated ecosystem fleet-based management of European fisheries. Marine Policy, 36(5), 1022-1032. 